\title{
Architecture As an Art of Immersion
}

\author{
Peter Sloterdijk \\ translated by A.-Chr. Engels-Schwarzpaul
}

Immersion and Immersionskunst (immersive art or art of immersion) are relatively new terms. They originate from the discourses of contemporary computer art, where immersion into synthetic perceptual worlds has been a lively topic since the late 1980s and early 1990s. We are dealing, therefore, with an arts practice that has come to be called immersion. Immersion, in this context, means to engage with one's immersion in artificial environments, assisted by technical equipment, for instance a virtual reality helmet or an electronic visor. Through these technologies, humans are finally taken seriously as beings for whom it is natural to immerse themselves - and not only in water, the 'wet element', but in elements and environments generally. The method has been common for some time, for instance in the context of pilots' training in flight simulators; however, the modern problem of hallucination management and immersive change was already anticipated in nineteenth century panoramas. A core aspect of artificial immersion, as a phenomenon, is the potential replacement of whole environments - not only of the images, usually framed, one looks at in galleries. Immersion as a method unframes images and vistas, dissolving the boundaries with their environment.

This necessarily leads us on to architecture, for it is properly considered, together with music, the original form in which the immersion of humans in artificial environments has been developed into a culturally controlled process. House building is a sort of basic version of immersion technology, while urbanism is the developed stage. Beyond urban development, however, there is also something like empire-building - that is, an architectonics of grand political forms, in whose construction military, diplomatic and psycho-semantic (or religious) functions all participate. Empire building becomes most visible when a large political structure is manifestly entrenched behind a long wall - one thinks automatically of the Roman limes and the Great Wall of China. Obviously, the immersive relationships of Roman and Chinese life were supposed to be performed behind such walls - Being understood as the Being-in-the-Empire of its citizens. We have meanwhile realised that one needs to be immersed in an empire's foundational narratives to experience it from inside. One cannot plunge into an empire's psycho-semantic immersive context without participating in its history. In this sense, history itself is nothing but a diving tank shared with cavorting fellow swimmers, and what is commonly called participation is, seen in this light, merely a naïve dipping into a one-dimensional context (while so-called critique can only be learnt through immersive changes, through bathing in alternating pools or contexts).

At this point, I would like to suggest an ad-hoc definition of modern totalitarianisms - a definition which seems obvious in this context. The twentieth century provided a series of attempts to dissolve the bipolarity or contradiction of European traditions, with the aim of telling one-dimensional power narratives yet again. This was perceivable in the mono-history of communism as much as in the monohistories of racial movements. The so-called totalitarianisms were attacks against the two-realm ontologies of Ancient Europe, against the freedom of changing contexts, against the ambiguity of double citizenship in the material and ideal realms. The twentieth century's most powerful ideologies were egalitarian and anti-dualist in orientation - they aimed at the construction of a monological context of success and power, which would no longer be vexed by changing perspectives and double existences. It is in this very context that the question of architecture's
Originally published as Sloterdijk, P. (2006). Architektur als Immersionskunst. Arch+, 178 (June), 58-63. Many thanks to Tim Adams, who drew our attention to this paper. 
meaning and function becomes poignant yet again. For, let us not forget, architecture is inherently a form of totalitarianism, a totalitarian practice by nature. Why? Because it is concerned with immersion, that is, with the production of an environment into which its inhabitants submerge, body and all. When one builds a house for oneself, one creates, as it were, the space-demon by which one will subsequently be possessed - and the architects aid and abet the production of various forms of an obsession with choice.

In this context, I would like to recall a philosophical dialogue from 1921 by the poet and philosopher Paul Valéry: "Eupalinos, or The Architect". Two figures from antiquity are conjured up, whom we know from the corpus platonicum: Socrates, on the one hand, and Phaedrus, on the other. This personnel isn't chosen entirely arbitrarily: the two had an unfulfilled love story in antiquity, and thus it seems plausible to bring them together, once again, under different circumstances. You may remember: Phaedrus was the only young man towards whom Socrates temporarily lost his self-control, on the occasion when, in a famous passage of the dialogue with the same title, Socrates felt a hint of Dionysian emotion - an admission Plato is otherwise not easily willing to make. This Phaedrus, of all people, is on the spot when it comes to talking about architecture. But why? Because the building of houses constitutes a problem of love - at least indirectly and subtly. Architecture's totalitarianism is a totalitarianism of love, of the love of space, of being enraptured by that which not only stands over against us but which envelopes us. By attempting to produce the space where we "open up completely", architecture articulates what Bachelard calls a topophile feeling. To build one's house amounts to generating the place and the envelope for one's own self-abandonment. This surrender to the built environment is commonly misconceived as the privately-owned home reading Paul VaIéry, however, provides us with reasons to distrust this superficial interpretation of dwelling.

To my knowledge, the neo-platonic dialogue, written at the time of the Weimar Bauhaus and the early designs of Le Corbusier, represents the first lucid document of what I would call the dawn of immersion in the twentieth century. Eight years later, the young Heidegger picks up the thread in Being and Time, in his analysis of being-in-the-world and being-attuned - a provocation to which Heidegger's teacher Husserl will oppose the analysis of the "Life-world" soon after (in his 1936 Crisis of European Sciences). Already in 1921, Valéry has Socrates say in his Eupalinos:

I feel compelled to chat about the arts. ... A painting, my dear Phaedrus, only covers a surface (like a plate or a wall) ... But a temple - approaching its forecourt, or even the interior of this temple - gives rise for us to a kind of absolute greatness in which we live.... We are, we move, we live in the work of a human being! ... We are taken in and mastered by the order he has chosen. We cannot escape him. (Valéry 1921)

Here, the totalitarian motif is clearly articulated. Incidentally, you may hear in Socrates' speech, somewhat anachronistically, an allusion to St Paul's address on the Areopagus in Athens (see chapter 17, Acts of the Apostles, New Testament). In a daredevil act of theological piracy, St Paul claims in this address the unknown God of the Greeks (for whom an altar had been erected in Athens - one never knows) for his Lord Jesus Christ. Paul, greatest of all pirates, looked for the weak spot in the Greek Pantheon and found it. Whereupon he suggests to the Athenians: You, the citizens of this proud city, you have, without quite knowing, already worshipped the true God too, namely the unknown God whose pseudonym I have the honour to disclose today. And here follows the great formula of the God in whom we live, 
and move, and have our being - I am quoting Luther's translation now, which older German speakers, who grew up in the protestant cultural ether, will still be able to hear. "In Him we live and move and have our being" - that is the unsurpassable, fundamental assertion of a Christian philosophy of space. It declares that humans aren't in the world just like that, that they do not lie about in the world like pebbles and other self-contained entities. Humans are in the world ecstatically, they exist in the mode of openness towards the world. And to be open is to be simultaneously here and in another place - there and here at once. This extends as far as thinking, according to the theologically honed statement, that humans or their souls wellnigh are and live in God, that is, in an alternative space, a super space which penetrates the profane and physical space. Now, Valéry has his Socrates state just this - or, rather, a variation of this - when the latter speaks about how we live, move and have our being in the work of a human being when we are in a building. Valéry knows exactly what he is quoting here and, by letting St Paul speak indirectly, he effectively appropriates the theological, psycho-semantic and immunological definition of the house.

This has far-reaching consequences. The house is a diving facility, as it were, in which the immersive comportment of humans towards the world is attended to. Dwelling is the original relationship of humans with their designed environment a fact, though, that is specifically elucidated only through the building of houses. To dwell in houses implies the art of substituting the original environment with a designed space. What the designed space has in common with nature is that it takes on the role of total environment. By being thoroughly man-made, however, it is at the same time nature's complete antithesis.

I propose that philosophy is a general theory of situations. To philosophise means to theorise situations. A situation is defined quite generally as a relationship of coexisting elements. The factors in this relationship can be listed in this way: situations are forms of coexistence of someone with someone and something in something. What does this mean? The first two figures are immediately intelligible: someone with someone - that indicates a personal association or a primitive social relationship; one also speaks occasionally of a dimension of intersubjectivity - a term that should be used only with care. The case of the two somethings is more complicated. The first something is meant to indicate our accessories, our equipment, thus the whole escort of objects that are attached to us and which, incidentally, were discovered as an independent theme for thinking and designing only during the twentieth century; philosophically, this occurred via Husserl's theory of the life-world and Heidegger's teachings on things that are ready-to-hand. Practically, it came about via the applied arts, which we meanwhile call design. The second something, however, refers to the spaces in which the togetherness of someone with someone takes place, it is the theme of topology, that is, the theory of space, of containers, of atmospheric wholes - all of which are, by the way, relatively recent inscriptions on the maps of philosophical disciplines.

Thus, the philosophical theory of situations is a theory of the togetherness of someone with someone and something in something. We can now see how this broaches the phenomenon or, rather, the basic relationship of immersion - and it should be clear that immersion only becomes genuinely interesting when collectives are caught up in shared immersive baths, from twosomes to dictatorships. It is fascinating to watch how Valéry's Socrates interlaces this with an acoustic analysis. According to him, architects not only build houses in which humans stay like 
bodies in bodies; they create spaces that are filled with life sounds, with language and music. To build is always also to produce a phonotype, a sonorous site which resonates with its inhabitants. Valéry remarks:

To be in the work of a human being like fish in the wave, to bathe in it thoroughly, to live in it, to belong to it, ... Were it not as if you lived in a mobile building, constantly renewed and reconstructed, in itself completely dedicated to the metamorphoses of a soul that would be the soul of space? ... Would it not appear as if [entities] surrounded you - you, a slave to the distributed presence of music? ... Would you not be enclosed together with it, and forced to be like a Pythia in the [Oracle's] chamber of vapours? (Valéry 1921)

These comments on the sojourn of humans in something with something and other(s) reveal the outlines of aesthetic totalitarianism in an artificial environment. Architecture is nothing else. It always implies voluntary bondage in a manmade environment. When you show people plans of houses, you propose to them their own enslavement. This proposal will be modified until the principal (wrongly so-called) says: "This is precisely the proposal for enslavement I would like to dwell in." The house in which I feel at ease is the demon I choose to be possessed by. But this does not only apply to the building of houses. There are two art forms, says Valéry, which envelope man in man: in the medium of stone in architecture, in the medium of air in music. Both art forms fill our space with synthetic truths.

It seems to me that the significance of Valéry's phrases can hardly be estimated highly enough. If the design of dwellings implies the proposition of a welcome surrender to the ambience, then this activity includes both an anthropological and a political function. As installations of immersive baths, dwellings explicate human Being as a three-dimensional project. In this regard, the architect works as a designer of immersions. This is particularly evident in the case of so-called interior architecture, which is in principle all about the artificial production of embedding situations. How far the necessity of this activity has spread into general awareness is demonstrated by the vast literature about interior fittings that has by now reached even the bookshops in railway stations - the countless publications about living in style, about adaptive use of old buildings, about luxurious kitchens and decorative images, air-conditioning, lighting design, the design of holiday homes and furniture. Taken together, they reveal how widely the message of embedment in self-selected micro-milieus, as the therapeutic maxim of the second half of the twentieth century, has reached the public. The entire industry of the intérieur stands by to awaken and differentiate such demands. Significantly, the awareness of being embedded became suddenly depoliticised after 1945 and disappeared from the lofty collectivist spheres - as though people never wanted to hear again that there are art forms which encase man in man. It is as though the collective memory had preserved the intuitive insight that the prominence of the totalitarian temptation grows in tandem with the extent of immersion in pooling units. Today it is obvious that the people living in the second half of the twentieth century no longer have any regard for empire-building. They seem to live according to the motto: no more grand success stories. They prefer to assemble those elements from home improvement centres which help them build immunity against totalitarian forms of immersion. To them, it seems immediately evident that they must weave the fabric for their happiness in smaller, more private dimensions. From this perspective, the building supply centres are the real surety of democracy. They house the popular support of everyday anti-totalitarianism. The moral of the story is obvious. Literally it would go like this: "Dwell in your own place and refuse 
the immersion in false collectives! Do not dwell in racial totalities! Do not engage with super-collectivisations, choose your furniture from your own supplies, take responsibility for the micro-totalitarianism of your dwelling circumstances. And never forget: in your homes, you are the infallible popes of your own bad taste."

We may no longer be citizens of two realms, but we still remain commuters between situations. However, since the Being-in designed spaces constitutes our fundamental condition, it seems obvious that architecture must remain conscious of its responsibility for the shaping of situations. Architecture is, above all, the design of immersions. Part of the ethics of the production of space is the responsibility for the atmosphere. To do the latter justice demands openness, ease of relocation, an appreciation for reversibility. Anthropologists can counsel architects always to take into consideration that humans are beings who oscillate between the desire to be embedded and the desire to break free.

\section{Reference}

Valéry, P. (1921) Eupalinos ou l'Architecte. Wikisource, la bibliothèque libre. Retrieved from http:/ www.livres-etebooks.fr/ebooks/Eupalinos_ou_I\%27Architecte-4461/ 